\title{
Design and Fabrication of Serrated Wing
}

\author{
Jitendra Singh, Devender Sharma \\ Department of Aeronautical Engineering, \\ Manav Rachna International Institute of Research and Studies, Faridabad, India
}

\begin{abstract}
This paper is an investigation on different theories evolved for noise reduction due to serrated trailing edge of an airfoil. The major objective is to explain the most relevant theory for involved in airfoil trailing edge noise reduction. This paper present the result of comparison and affiliation between Howe's theory, Oerleman"s theory , Gruber noise reduction theory at different Reynolds number. Limitation discovered comparing these theories for transforming flat plate aerofoil to serrated trailing edge aerofoil can be overcome by novel surface treatment and also with different non flat design comprised of poro serrated material.
\end{abstract}

\section{INTRODUCTION}

The noise produced by the airfoil is due to the interaction of flow disturbance with the trailing edge of airfoil self-noise mechanism In term of airfoil self-noise reduction by passive flow control, one of the most commonly used method is inspired by the Owl. Trailing edge noise level can be reduce by modifying:-

- The trailing edge geometry so that flow disturbance are scattered into sound with reduced efficiency

- $\quad$ Reduced the correlation length of turbulence near the trailing edge.

Trailing edge noise model for serrated wing is mainly obtained Howe's theory. According to Howe's theory trailing edge noise can be significantly reduced with the addition of trailing edge serrations due to a reduction in the effective spanwise length of the trailing edge that contributes to noise generation. In deriving the serration noise reduction model, Howe made a number of assumptions and approximations such as that the surface pressure frequency spectrum close to the trailing edge is unchanged by the presence of trailing edge serrations. Therefore Howe's theory states that the magnitude of this noise reduction is dependent on the height and geometrical wavelength of the serrations and on the frequency of sound. The sound generated by large eddies whose length scales are greater than the amplitude of the serrations (low frequency sound) is unaffected by the presence of the serrations and hence significant noise reductions are only expected in the high frequency region.

Gruber the sawtooth geometry explains the interaction between the vertical structure and the local turbulent boundary layer result in redistribution of momentum and turbulent shear stress near the sawtooth edges affecting he efficiency of self-noise radiation. For Gluber noise reduction can be achieved by fulfilling two conditions:

The serration length is of same order as the turbulent boundary layer thickness near the trailing edge

- The serration angle, giving the appearance of a sharp sawtooth.

\begin{tabular}{|l|l|l|l|}
\hline S.No & $\begin{array}{l}\text { MODEL } \\
\text { (DESCRIPTION) }\end{array}$ & EXPERIMENTATION & RESULT \\
\hline $\mathbf{1 .}$ & $\begin{array}{l}\text { NACA 64418 airfoil } \\
\text { a steel body and a detachable } \\
\text { trailing edge plate made from } \\
\text { brushed aluminum } \\
\text { Cambered profile 0.16m \& } \\
0.45 \mathrm{~m} \text { span }\end{array}$ & $\begin{array}{l}\text { Oerlemans investigation } \\
\text { At high Reynolds numbers } \\
(\mathrm{Rec} \approx 1.6 \times 106), \text { optimizing the airfoil shape } \\
\text { for low noise emission and adding trailing edge } \\
\text { serrations. }\end{array}$ & $\begin{array}{l}\text { Decrease in noise levels by } \sim 3 \mathrm{~dB} \text { at } \\
\text { frequencies below } 1 \mathrm{kHz} \text { and increase } \\
\text { the noise levels above this frequency } \\
\text { without any adverse effect. Therefore, } \\
\text { an average reduction of } \sim 6 \mathrm{~dB} \text { in the } \\
\text { radiated noise levels }\end{array}$ \\
\hline $\mathbf{2 .}$ & $\begin{array}{l}\text { NACA 651-210 airfoil with } \\
\text { serrated trailing edge }\end{array}$ & $\begin{array}{l}\text { Gruber noise reduction examination. At } \\
\text { Reynolds numbers } 2.0 \times 10^{\wedge} 5<\operatorname{Rec}<8.3 \times 10^{\wedge} 5\end{array}$ & $\begin{array}{l}\text { Noise reductions of up to } 7 \mathrm{~dB} \text { were } \\
\text { achieved at low frequencies }(<2 \mathrm{kHz}) \\
\text { and } \\
\text { observed at high frequencies. }\end{array}$ \\
\hline
\end{tabular}

From Azarteyvand model theory it is found that the physical mechanism of sound reduction by using serrations is the destructive interference effect due to the out-of-phased scattered pressure in the vicinity of the trailing-edge. Two geometrical parameters are found critical in determining the sound reduction. First, the root-to-tip length needs to satisfy k1h 1 to ensure sufficient phase differences are induced along the edge. Second, the value of k1he 1 is required to ensure the phase differences induced as above are "fully correlated". For the boundary layer flow above a flat plate, this can be equivalently expressed as the slope $4 \mathrm{~h} / \lambda$ of the sawtooth edges should be large enough. The sound reduction generally increases as the slope increases. But if the serrations are already sharp enough, further increasing the slope only affects high frequencies.

1) A Study of the Silent Flight of the Owl

\section{LITERATURE REVIEW}

Many species of owl, including the barn and barred owl, use both visual and bi-aural location to search for prey around dusk and at night. Their bi-aural location system has a maximum sensitivity between $3-6 \mathrm{kHz}$ although the hearing of the owl has an upper limit in excess of $20 \mathrm{kHz}$. Its prey, typically voles and mice, squeak and squeal in the frequency range of 3-6 kHz and this range of frequency includes the rustling of leaves made by prey. The hearing of these prey is acute between $2-20 \mathrm{kHz}$. The owl in both gliding and flapping flight generates noise at low frequencies below $2 \mathrm{kHz}$, but 
is almost totally silent at frequencies above $2 \mathrm{kHz}$ It was Lt.Comdr.GrahamR.N.1Who observed the owl' swing feathers differed from almost all other birds by:

(1)The addition of feathers in the form of a leading Edge comb.

(2)A fringe formed by the feathers at the trailing edge.

(3)A velvety covering on the wing upper surface and a downy lower surface as well as thick down on its legs

The current research on the silent flight of the owl is part of our aim towards a greater understanding of the increased noise at ground level made by aircraft in flight, other than engine noise, especially in the landing phase, when the aircraft are flying at low speeds and high incidence. It would be remarkable indeed if the noise reduction and noise suppression devices, developed by the owl during its long period of evolution, had some application towards are duction in the landing phase of current civil transports. Nevertheless if we ignore the technical and scientific mechanisms associated with the owl's noise suppression system we may miss one of the golden opportunities to generate the quiet transport aircraft of the future.

\section{2) Noise reduction mechanism of a flat plate serrated trailing edge}

This paper presents the results of an experimental investigation exploring the noise reduction trailing edge serrations on a flat plate at low-to-moderate

Reynolds Number $(1.6 \times 105<\operatorname{Rec}<4.2 \times 105)$. The main objective are:

a) To present acoustic and flow data for two different serration geometries at a variety of flow speeds

b) To compare experimental measurements with theoretical noise reductions predicted using the theory of Howe and

c) To investigate how serrations affect noise production at the trailing edge.

In this experimental investigation the noise reduction achieved with trailing edge serrations was found to depend on Strouhal number, St $\delta=f \delta / \mathrm{U} \infty$, and serration wavelength which is contradicting to theory, wide serrations with larger wavelength to amplitude ratio, $\lambda / \mathrm{h}$, were found to outperform narrow ones by achieving higher attenuation levels and no noise increase in the mid frequency region.

\section{3) On the mechanisms of serrated airfoil trailing edge noise reduction}

This paper is based on observation of the mechanism involved in airfoil trailing edge noise reduction and noise increase observed at trailing edge due to sawtooth serration. The experiment is done on NACA6512 airfoil with set of more than 30 sawtooth geometries. It shows that the frequency above which the noise increased is fixed by STROUHAL number .The observations takes place in open jet wind tunnel at various velocities. The observed values are compared with HOWE's theory which shows noise reduction levels predicted by Howe are much greater than the measured ones. The main parameters which are investigated in this paper include the unsteady wall pressure power spectral densities (PSD), coherence functions and heat transfer characteristics across a full sawtooth surface. It shows that noise reductions takes place up to $7 \mathrm{~dB}$ over wide frequency range, whereas the noise is increased by $3 \mathrm{~dB}$ at higher frequency. As per Howe's theory the angle between the sawtooth serration must be less than 45 degrees to reduce the noise at the trailing edge.

\section{4) A Trailing-Edge Noise Model for Serrated Edges}

This paper is concerned with the development of a theoretical model for the prediction of the sound radiated by serrated trailing-edges. The broadband noise, induced by the interaction of boundary layer with the airfoil trailing-edge, known as the turbulent boundary layer trailing-edge noise, plays a significant role in the overall airframe noise. When a turbulent boundary layer convects past the trailing-edge, the unsteady pressure with a wavenumber in the hydrodynamic range is scattered into sound with the wavenumbers in the acoustic range, leading to noise radiated from trailing-edge. Both experiments and theories reveal that the radiated sound power varies with the characteristic flow velocity to the power of five, which is thus more efficient than that when the airfoil is absent at low Mach numbers. Howe proposed a theoretical model to predict the sound generated by the serrated trailing-edge of both the sinusoidal and sawtooth profiles. Investigated analytically the trailing-edge noise reduction using novel serrations, namely, sawtooth, sinusoidal, slitted, slitted-sawtooth and sawtooth-sinusoidal. The noise reduction performance is believed to depend on two main non dimensional parameters, $\mathrm{k} 1 \mathrm{~h}$ and $\mathrm{k} 1 \mathrm{ly} 0(\omega) \sigma$. the condition that $\mathrm{k} 1 \mathrm{~h}>>1$, that $|\mathrm{an}|$ decreases as $\mathrm{k} 1 \mathrm{~h}$ increases. Therefore, for a fixed serration geometry high frequencies are preferable in terms of noise reduction. This also means that the rootto-tip length determines the effective frequency range where sound reduction can be achieved.

\section{5) Airfoil self-Noise reduction by non-flat plate type T.E serration}

This paper aims to reduce the airfoil trailing edge self-noise by employing non-flat plate type trailing edge serrations. This configuration offers better structural strength and integrity, as well as a more straightforward manufacturing process compared to the conventional flat plate type serrations. To increase the effectiveness of the proposed serration geometry a hybrid configuration composed of a non-flat plate type trailing edge serration with woven-wire mesh screen is employed for the reduction of the narrowband vortex shedding noise experiment setup is wind tunnel which can achieve turbulence intensity as low as $0.1 \%$ and Mach number as high as 0.3 , while maintaining a low background noise. The airfoil under investigation here was held by side plates and attached to the nozzle lips. In this study, airfoil self-noise 
pertaining to 15 to the jet axis was examined, which is larger than the "effective" angle due to downwash deflection of the incident flow by the airfoil and affects the pressure gradient distribution on the airfoil surfaces. Turbulent boundary layers were artificially generated by placing rough sandpaper near the leading edge on both of the suction and pressure surfaces. The wall pressure spectra differ considerably at the pressure surface. Without the use of the boundary layer trip, the wall pressure spectra are of comparatively lower level and less smooth than when tripping is applied. The boundary layer becomes turbulent when the trip is introduced as manifested by the considerably higher wall pressure spectral level with the characteristic high frequency decay rate of approximately $\mathrm{f}^{-5}$. The relationship between the serration parameters such as $\mathrm{k}, \mathrm{u}$ and $2 \mathrm{~h}$ and the radiated broadband noise has been studies theoretically by Howe [6] whereby greatest noise reductions are predicted in the high frequency range, $\mathrm{xh} / \mathrm{U} 1$ and for $\mathrm{u}<45$, for which noise reductions of $10 \log 10[1+$ $(4 \mathrm{~h} / \mathrm{k}) 2 \mathrm{~dB}$ are predicted. This implies that an $18 \mathrm{~dB}$ broadband noise reduction can theoretically be achieved by one of the serration configurations investigated in the current study for which $\mathrm{h} / \mathrm{k} 2$. Gruber et al. has also found that the serration length $(2 \mathrm{~h})$ must be greater than the trailing edge boundary layer thickness (i.e. $\mathrm{h} / \mathrm{d}>0.5)$ for significant noise reductions to occur. Of all the 36 different sawtooth serrated edges that were tested by Gruber et al., maximum noise reductions were limited to $7 \mathrm{db}$. Gruber et al. also observed noise increases of up to $3 \mathrm{~dB}$ at high frequencies, which they attributed to the presence of small jets through the troughs of the serration. Therefore its found that the non-flat plate serration not only reduces the broadband self-noise significantly, but also eliminates the high-frequency noise.

6) Experimental investigation of airfoil self-noise and turbulent wake reduction by the use of trailing edge serrations This paper shows the comparison of the measurements of the trailing edge self-noise reduction obtained using sawtooth serrations on a NACA651210 airfoil to the theoretical noise reduction predictions developed by Howe. This also focuses on the effect of the sawtooth serrated edges on steady and unsteady aerodynamics around the airfoil. The important aspect is looked carefully about the turbulence in the wake, which is of concern for airfoil turbulence interaction noise. An experimental study was conducted in the open jet wind tunnel which reveals noise reductions of up to $5 \mathrm{~dB}$ over a wide frequency range by the introduction of these trailing edge designs. This paper also presents the noise measurements for a range of jet speeds and sawtooth geometries. The airfoil is at 5 degree angle of attack and the boundary layer is made turbulent by tripping. In addition, measurements of the static pressure coefficient distribution along the chord of the airfoil are also reported. This is to allow the effects on lift to be observed. The drag coefficient, obtained from wake velocity measurements downstream of the airfoil, shows no significant change due to the introduction of serrations. Noise measurements are compared to the theory derived by Howe for serrated trailing edges. Large differences between the predicted and measured noise reductions are obtained. Experimental data show that irrelevant sources of noise in the high frequency range, possibly due to the generation of vorticity along the wetted edges of the trailing edge, reduces the potential noise reduction predicted by the theoretical model. Detailed hot wire measurements of the mean and turbulent flow in the boundary layer over a single sawtooth shows that serrated edges have a small effect on the development of the boundary layer in the free stream direction. Measurements of the free stream velocity in the airfoil wake at various locations downstream of the trailing edge reveal a small reduction of the turbulence in the wake for serrated edges. It also shows more the turbulent length scale in the far wake increases for the sharper sawtooth, while decreases for the large base sawtooth. This work is relevant to reducing the noise from aircraft engines, aircraft wings and wind turbines.

7) An Investigation on the near-field turbulence and radiated sound for an airfoil with trailing edge serrations

This study is on the mechanism of the turbulence broadband noise reduction for an airfoil with the trailing edge serrations. An open jet wind tunnel test of airfoil SD2030 with and without trailing edge serrations was compared and observed. The far field acoustics DSP and fluctuating turbulence information around airfoil was compared for both straight and serrated trailing edge. It is shown that trailing edge noise could be effectively reduced with the using of serrated trailing edge, and the magnitude and frequency range of airfoil trailing edge noise reduction are changed with the increase of main flow velocity. In the frequency range of $10 \mathrm{kHz}$, the largest noise reduction of sound pressure level is about $5 \mathrm{~dB}$ with the using of serrated trailing edge in the test flow speed range. The predicted results of Howe's theoretical model are in a good agreement with the experiment results. However, Howe's theoretical model over-predicted noise reduction levels in high frequency while lowly-predicted the noise suppression in low frequency range. Near-field turbulence measurements show that serrated trailing edge could reduce turbulence strength on some directions and on some positions, and could also increase turbulence strength on other directions and on other positions. This result indicates that noise reduction mechanism with the serrated trailing edge is very complicated.

8) Results of wind tunnel study on the reduction of airfoil self-noise by the application of serrated blade trailing edge This paper deals with explanation of results with different series of airfoil to explore the noise reducing potential of serrated trailing edges experiments performed

9) Trailing edge noise reduction using novel surface treatment

This paper deals with control technique of trailing edge noise radiation due to large coherent turbulent structure. Novel surface treatment is used to indicate the capability of proposed trailing edge technique of noise reduction. It is designed in such a manner that it can demonstrate the flow and noise measurement values carried out at different surface. The 
experiments were carried out in an open wind tunnel of Yazd University. In the present wind tunnel, the centrifugal forward blades types fan creates low broadband noise. Microphones dimension dimensions are $2.5 \mathrm{~mm}$ in diameter, $2.5 \mathrm{~mm}$ in height and with a circular sensing area of $0.8 \mathrm{~mm}$. Microphones are embedded in the flat plate under a pinhole of diameter $0.4 \mathrm{~mm}$. All pinholes are created by drilling the flat plate using the accurate drill machine. Due to the its thickness the pinhole can be created vertically and positioned microphones under the pinholes at the T.E. near the T.E the, microphones have been installed inside the flat plate parallel to the surface. Measurements were carried out at zero angle of attack for three different free stream velocities, $U \infty=10,15$, and $20 \mathrm{~m} / \mathrm{s}$, corresponding to chord Reynolds numbers of $\operatorname{Rec}=3.87 \times 105,5.8 \times 105$, and $7.73 \times 105$ respectively As the turbulent flow field around the trailing edge is the source of trailing edge noise, velocity measurements near the trailing edge of the flat plate with and without surface treatments (baseline) are studied to gain insight into the mechanism by which fences affect flow structure. Results revealed that the surface treatment can significantly reduce the surface pressure fluctuations near the trailing edge, lessen the spanwise coherence and spanwise length-scale, and reduce the convection velocity of the turbulent structures. It has also been shown that the cross-correlation between the turbulent structures within the outer region of the boundary layer and the unsteady surface pressure can be significantly reduced.

\section{0) Poro-Serrated Trailing-Edge Devices for Airfoil Self-Noise Reduction}

This paper represents the continuation of the works previously published in Chong et al. And used several non-flat plate serrated trailing edges for the reduction of airfoil self-noise. The overall noise performance of the non-flat plate trailingedge serration type can be improved by the concept of poro serrated used in the current work. The bluntness-induced vortex shedding tonal noise can be suppressed by filling the gaps between the adjacent members of the saw tooth by the use of porous metal, synthetic foams, or thin brush bundles. Most important, up to $7 \mathrm{~dB}$ turbulent boundary layer-trailingedge broadband noise reduction can simultaneously be achieved without compromising the aerodynamic performances in lift and drag. The poro-serrated trailing edges do not cause any noise increase throughout the frequency range investigated here. The reduction of the turbulent broadband noise is primarily caused by the serration effect, but under a condition that the saw tooth surface must be solid and nonporous. The primary role of the porous metal foams in a poroserrated trailing edge is to suppress the vortex shedding tonal noise. However, an optimum selection of the porous material is also found to be able to further reduce the broadband noise level. The new serrated trailing-edge concept developed here has the potential to improve the industrial worthiness of the serration technology in achieving low noise radiation in fan and turbine blade

\section{1) Optimization of the poro-serrated trailing edges for airfoil broadband noise reduction}

This paper deals with number of poro serrated trailing edge devices in airfoil NACA0012. Poro serrated material has a good noise absorbing capability. So here poro serrated material is used between saw tooth trailing edge. The main objective of this work is to determine whether multiple mechanism on the broadband noise reduction can co-exist on the poro serrated trailing edge. Good broadband noise reduction be achieved at high frequency but vortex shedding tone at low frequency could not be completely suppressed at high velocity when saw toot gaps are filled with porous material of low flow resistivity. When the saw tooth gaps are filed with porous material of high flow resistivity, no vortex shedding is present but the serration effect on the broadband noise reduction becomes less effective. At optimal choice of flow resistivity for a poro serrated configuration has been identified where it can surpass the conventional serrated trailing edge of same geometry by achieving a further $1.5 \mathrm{db}$ reduction in the broadband noise while completely suppressing the vortex shedding tone. A weakened turbulent boundary layer noise scattering at the poro serrated trailing edge is reflected by the lower turbulence intensity at the near wake centerline across the whole span wise wavelength of the saw tooth. 


\section{DISCUSSION}

This section of the paper deals with the explanation of different types of airfoil models

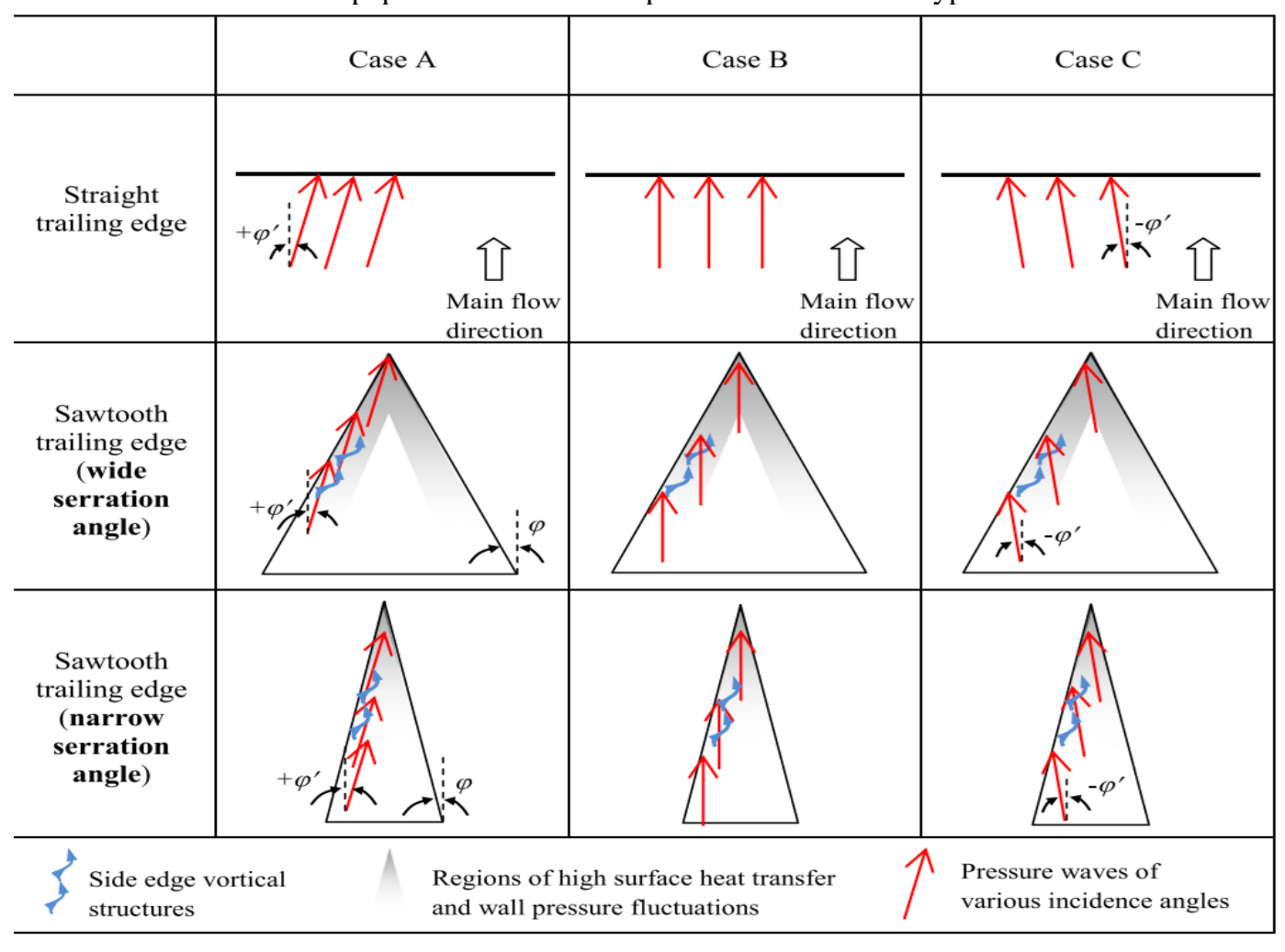

\begin{tabular}{|c|c|c|c|}
\hline S.No & $\begin{array}{l}\text { MODEL } \\
\text { (DESCRIPTION) }\end{array}$ & EXPERIMENTATION & RESULT \\
\hline 1. & $\begin{array}{l}\text { A steel body and a detachable } \\
\text { trailing edge plate made from } \\
\text { brushed aluminum with span } \\
450 \mathrm{~mm} \text { and a thickness of } 6 \\
\mathrm{~mm} \text {. The trailing edge (TE) is } \\
\text { asymmetrically beveled at an } \\
\text { angle of } 12 \circ \text {. Three } 0.5 \mathrm{~mm} \\
\text { thick trailing edge plates with } \\
\text { a straight. }\end{array}$ & $\begin{array}{l}\text { The experiment is performed in anechoic wind } \\
\text { tunnel test chamber is } 1.4 \mathrm{~m} \times 1.4 \mathrm{~m} \times 1.6 \mathrm{~m} \\
\text { (internal dimensions) and has walls that are } \\
\text { acoustically treated with foam wedges to } \\
\text { approximate a free environment at frequencies } \\
\text { above } 250 \mathrm{~Hz} \text {. The facility contains a } \\
\text { contraction outlet that is rectangular in cross- } \\
\text { section with dimensions of } 75 \mathrm{~mm} \times 275 \mathrm{~mm} \text {. } \\
\text { Acoustic measurements were recorded at a } \\
\text { single observer location using a B\&K } 1 / 2 " \\
\text { microphone located } 554 \mathrm{~mm} \text { directly below the } \\
\text { trailing edge of the reference plate. }\end{array}$ & $\begin{array}{l}\text { Trailing edge serrations were found to } \\
\text { minimize broadband noise levels at } \\
\text { low frequencies up to } 3 \mathrm{~dB} \text { and achieve } \\
\text { significant attenuation up to } 13 \mathrm{~dB} \text { of } \\
\text { blunt vortex shedding noise at high } \\
\text { frequencies without modifying the } \\
\text { directivity of the radiated noise. The } \\
\text { noise reduction achieved with trailing } \\
\text { edge serrations was found to depend on } \\
\text { Strouhal number, } \\
\mathrm{St} \delta=\text { fo/Uœ and serration wavelength. } \\
\text { But significant difference as explained } \\
\text { by Grubers explanation. Where as }\end{array}$ \\
\hline 2. & $\begin{array}{l}\text { A steel body and a detachable } \\
\text { trailing edge plate made from } \\
\text { brushed aluminum with span } \\
450 \mathrm{~mm} \text { and a thickness of } 6 \\
\mathrm{~mm} \text {. The trailing edge (TE) is } \\
\text { asymmetrically bevelled at an } \\
\text { angle of } 12 \circ \text {. Three } 0.5 \mathrm{~mm} \\
\text { thick trailing edge plates with } \\
\lambda / \mathrm{h}=0.2 \text {, narrow serration }\end{array}$ & Same as above & $\begin{array}{l}\text { due to interference between acoustic } \\
\text { radiation produced at the root and the } \\
\text { tip of the serrations. } \\
\text { - St } \delta<0.13: \text { Region of noise } \\
\text { attenuation (R1). } \\
\text { - } 0.13<\mathrm{St} \delta<0.7 \text { : Region of noise } \\
\text { increase }(\mathrm{R} 2) \text {. } \\
-0.7<\mathrm{St} \delta<1.4: \text { Region of attenuation } \\
\text { in the blunt trailing edge vortex } \\
\text { shedding noise component (R3). } \\
\text { Therefore, found to depend on } \\
\text { Strouhal number but significant } \\
\text { difference in Strouhal numbers } \\
\text { explained by Grubers explanation. } \\
\text { From The experiment maximum } \\
\text { attenuation is predicted to be } 26 \mathrm{~dB} \\
\text { which criticize the theoretical noise } \\
\text { reduction prediction of Howe's theory }\end{array}$ \\
\hline 3. & $\begin{array}{l}\text { A steel body and a detachable } \\
\text { trailing edge plate made from } \\
\text { brushed aluminum with span } \\
450 \mathrm{~mm} \text { and a thickness of } 6 \\
\end{array}$ & Same as above. & $\begin{array}{l}- \text { St } \delta<0.2 \text { : Region of noise attenuation } \\
(\mathrm{R} 1) . \\
\cdot 0.2<\text { St } \delta<0.7 \text { : Region of equivalent } \\
\text { noise levels (R2). }\end{array}$ \\
\hline
\end{tabular}




\begin{tabular}{|l|l|l|l|}
\hline $\begin{array}{l}\text { mm. The trailing edge }(\mathrm{TE}) \text { is } \\
\text { asymmetrically beveled at an } \\
\text { angle of } 12 \circ \text {. Three } 0.5 \mathrm{~mm} \\
\text { thick trailing edge plates with } \\
\lambda / \mathrm{h}=0.6, \text { wide serration }\end{array}$ & $\begin{array}{l}\bullet 0.7<\mathrm{St} \delta<1.4: \text { Region of attenuation } \\
\text { in blunt trailing edge vortex } \\
\text { shedding noise component (R3). } \\
\text { Therefore, found to depend on } \\
\text { Strouhal number but significant } \\
\text { difference in Strouhal numbers } \\
\text { explained by Grubers explanation } \\
\text { From The experiment maximum } \\
\text { attenuation is predicted to be 17d } \\
\text { which agrees theoretical noise } \\
\text { aeduction prediction of Howe's theory. }\end{array}$ \\
\hline
\end{tabular}

\begin{tabular}{|c|c|c|c|}
\hline S.No & $\begin{array}{l}\text { MODEL } \\
\text { (DESCRIPTION) }\end{array}$ & EXPERIMENTATION & RESULT \\
\hline 1. & $\begin{array}{l}\text { NACA } 6512-10 . \\
\text { A steel body of } 0.1 \mathrm{~m} \text { length\& } \\
\text { detachable trailing edge. } \\
\text { Cambered profile } 0.16 \mathrm{~m} \mathrm{\&} \\
0.45 \mathrm{~m} \text { span }\end{array}$ & $\begin{array}{l}\text { Done in ISVR open jet wind tunnel. } \\
\text { Measurements of far field noise are performed } \\
\text { using } 19 \text { B\&K microphones. These } \\
\text { microphones are placed at } 45 \& 135 \text { deg. Noise } \\
\text { is recorded for four velocities and } 5 \text { angles of } \\
\text { attacks. }\end{array}$ & $\begin{array}{l}\text { Obtained values reveals reduction of } \\
\text { noise up to } 5 \mathrm{~dB} \text {. But it shows large } \\
\text { differences with respect to Howe's } \\
\text { theory. Irrelevant source of noise is } \\
\text { obtained due to vorticity at high } \\
\text { frequency range. }\end{array}$ \\
\hline 2. & $\begin{array}{l}\text { SD } 2030 \\
4 \% \text { camber \& } 8 \% \text { thickness. } \\
150 \mathrm{~mm} \text { chord \& } 300 \mathrm{~mm} \text { span }\end{array}$ & $\begin{array}{l}\text { Done in open jet wind tunnel with air supplied } \\
\text { up to } 0.3 \text { Mach number. Linear unequal } \\
\text { spacing of microphone array comprising of } 31 \\
\text { microphones was placed around the airfoil to } \\
\text { analyses the strength of noise. }\end{array}$ & $\begin{array}{l}\text { The trailing edge noise was reduced, } \\
\text { and the predicted results of Howe's } \\
\text { theory were in good agreement with } \\
\text { experimented values. }\end{array}$ \\
\hline 3. & $\begin{array}{l}\text { NACA } 6512-10 . \\
\text { A steel body of } 0.1 \mathrm{~m} \text { length\& } \\
\text { detachable trailing edge. } \\
\text { Cambered profile } 0.16 \mathrm{~m} \mathrm{\&} \\
0.45 \mathrm{~m} \text { span }\end{array}$ & SAME AS IN 1ST. & $\begin{array}{l}\text { SAME RESULT. It also shows that } \\
\text { noise reductions take place up to } 7 \mathrm{~dB} \\
\text { over wide frequency range, whereas } \\
\text { the noise is increased by } 3 \mathrm{~dB} \text { at higher } \\
\text { frequency. As per Howe's theory the } \\
\text { angle between the saw tooth serration } \\
\text { must be less than } 45 \text { degrees to reduce } \\
\text { the noise at the trailing edge. }\end{array}$ \\
\hline
\end{tabular}

\section{Technique for noise control by surface pressure}

Airfoil self-noise is produced due to the interaction of unsteady flow in the form of fluid turbulence with the surface of airfoil. There are a variety of specific noises generating components attached to the airfoil. The physical process of T.E noise was described by Roger and Moreau. For the reduction of T.E noise, many passive airfoil noise control methods have been developed as described in the given table.

\begin{tabular}{|c|c|c|c|c|}
\hline \multirow[t]{2}{*}{ Model (T.E)* } & \multicolumn{3}{|l|}{ Dimension } & \multirow[t]{2}{*}{ Effect } \\
\hline & \begin{tabular}{|l|} 
Chord \\
length $(\mathrm{mm})$ \\
\end{tabular} & $\operatorname{Span}(\mathrm{mm})$ & Thickness(mm) & \\
\hline T.E serration & 580 & 456 & 8 & \multirow{2}{*}{$\begin{array}{l}\text { Lead to the reduction in the effective spanwise } \\
\text { length of the T.E. }\end{array}$} \\
\hline & & & & \\
\hline T.E brushes & 580 & 456 & 8 & \multirow{2}{*}{$\begin{array}{l}\text { Have indicated a significant noise-reduction } \\
\text { potential in wind tunnel tests on a Flat } \\
\text { Plate and on a 2-D airfoil. }\end{array}$} \\
\hline & & & & \\
\hline Porous T.E & 580 & 456 & 8 & \multirow{2}{*}{$\begin{array}{l}\text { These can also reduce the sound pressure level } \\
\text { at low to mid frequencies. }\end{array}$} \\
\hline & & & & \\
\hline Airfoil shape optimization & 580 & 456 & 8 & \multirow{2}{*}{$\begin{array}{l}\text { The thickness or the curve gradient can } \\
\text { significantly affect the flow around the airfoil } \\
\text { leading to the improvement in both the } \\
\text { Aerodynamics and aeroacoustic performance } \\
\text { of the airfoil. }\end{array}$} \\
\hline & & & & \\
\hline T.E morphing & 580 & 456 & 8 & \multirow{2}{*}{$\begin{array}{l}\text { Reduce the airfoil trailing edge noise over a } \\
\text { wide range of flow speeds } \\
\text { and angle of attack. }\end{array}$} \\
\hline & & & & \\
\hline Upstream surface treatment & \multicolumn{3}{|c|}{-------------------------- } & -------------------- \\
\hline
\end{tabular}

*under develop

Not defined 
Optimizing serrated aerofoil with the help of porous material material

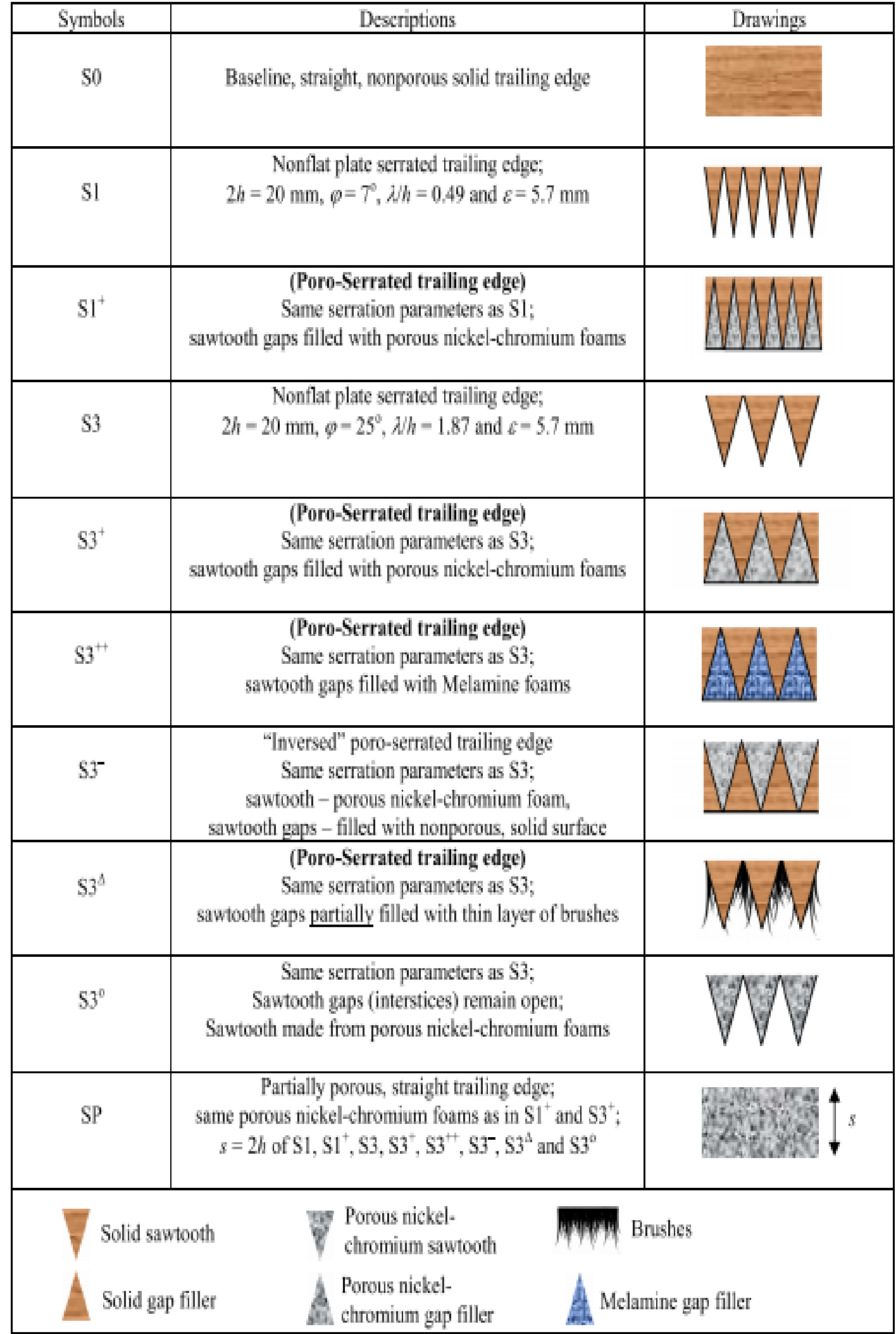




\begin{tabular}{|c|c|c|c|}
\hline S.NO & MODEL & EXPERIMENTATION & RESULT \\
\hline 1 & $\begin{array}{l}\text { NACA } 0012 \text { The chord length } \mathrm{C} \text { of } \\
\text { the airfoil is } 150 \mathrm{~mm} \text {, and the width } \\
\text { is } 450 \mathrm{~mm} \text {. Between the leading-edge } \\
\mathrm{x} / \mathrm{C}=0 \text { and } \mathrm{x} / \mathrm{C}=0.79 \text {, the original } \\
\mathrm{NACA} 0012 \text { airfoil profile is } \\
\text { unmodified, where } \mathrm{x} \text { is the } \\
\text { streamwise direction. Further } \\
\text { downstream } 0.79<\mathrm{x} / \mathrm{C}<1.0 \text {, is a } \\
\text { section that can be removed and } \\
\text { replaced by a serration profile. }\end{array}$ & $\begin{array}{l}\text { Solid sawtooth, solid gap filler, porous nickel } \\
\text { chromium sawtooth, porous nickel chromium } \\
\text { gap filler, brushes and melamine gap filler are } \\
\text { used in this experimentation in airfoil } \\
\text { NACA0012 to reduce the overall noise } \\
\text { performance of the non-flat plate trailing-edge } \\
\text { serration }\end{array}$ & $\begin{array}{l}\text { For all the trailing edge devices } \\
\text { investigated in the study, two } \\
\text { main groups can be formed based } \\
\text { on the noise performance Group } \\
\text { A(S3,S3+ and S3^)is } \\
\text { characterized by solid sawtooth } \\
\text { serration and every member } \\
\text { within this group consistently } \\
\text { demonstrated a significant } \\
\text { trailing edge noise reduction } \\
\text { Group B (S3- and S3*) where } \\
\text { every member within the group } \\
\text { use sawtooth made from porous } \\
\text { nickel chromium foam offers no } \\
\text { advantage on the broadband noise } \\
\text { reduction even though it shares } \\
\text { the same geometric parameters of } \\
\text { serration as Group A }\end{array}$ \\
\hline
\end{tabular}

[1] M. Herr and W. Dobrzynski, "Experimental investigations in low-noise trailing-edge design,” AIAA J., vol. 43, no. 6, pp. 1167-1175, May 2005.

[2] M. S. Howe, "Noise produced by a sawtooth trailing edge," J. Acoust. Soc. Am., vol. 90, no. 1, pp. 482-487, Jul. 1991.

[3] M. S. Howe, "Aerodynamic noise of a serrated trailing edge," J. Fluids Struct., vol. 5, no. 1, pp. 33-45, Jan. 1991.

[4] M. Gruber, P. F. Joseph, and T. P. Chong, "Experimental investigation of airfoil self noise and turbulent wake reduction by the use of trailing edge serrations," in 16th AIAA/CEAS Aeroacoustics Conference (31st AIAA Aeroacoustics Conference), 2010.

[5] M. Gruber, P. F. Joseph, and T. P. Chong, "On the mechanisms of serrated airfoil trailing edge noise reduction," in 17th AIAA/CEAS Aeroacoustics Conference 2011 (32nd AIAA Aeroacoustics Conference), 2011.

[6] G. M. Lilley, “A study of the silent flight of the owl," in 4th AIAA/CEAS Aeroacoustics Conference, 1998.

[7] A. A. Oberai, F. Roknaldin, and T. J. R. Hughes, "Computation of trailing-edge noise due to turbulent flow over an airfoil," AIAA J., vol. 40, no. 11, pp. 2206-2216, May 2002.

[8] D. J. Moreau, L. A. Brooks, and C. J. Doolan, "On the noise reduction mechanism of a flat plate serrated trailing edge at low-to-moderate Reynolds number," in 18th AIAA/CEAS Aeroacoustics Conference (33rd AIAA Aeroacoustics Conference), 2012.

[9] F. V. Hutcheson and T. F. Brooks, "Effects of Angle of Attack and Velocity on Trailing Edge Noise Determined Using Microphone Array Measurements," Int. J. Aeroacoustics, vol. 5, no. 1, pp. 39-66, Jan. 2006.

[10] S. Moreau and M. Roger, "Effect of airfoil aerodynamic loading on trailing-edge noise sources," AIAA J., vol. 43, no. 1, pp. 41-52, May 2005.

[11] T. P. Chong, A. Vathylakis, P. Joseph, and M. Gruber, "On the noise and wake flow of an airfoil with broken and serrated trailing edges," in 17 th AIAA/CEAS Aeroacoustics Conference 2011 (32nd AIAA Aeroacoustics Conference), 2011.

[12] F. V. Hutcheson and T. F. Brooks, "Measurement of Trailing EDGE Noise Using Directional Array and Coherent Output Power Methods," Int. J. Aeroacoustics, vol. 1, no. 4, pp. 329-353, Oct. 2002.

[13] A. Vathylakis, T. P. Chong, and P. F. Joseph, "Poro-serrated trailing-edge devices for airfoil self-noise reduction," AIAA J., vol. 52, no. 11, pp. 33793394, Jul. 2015.

[14] M. Roger and S. Moreau, "Extensions and limitations of analytical airfoil broadband noise models," Int. J. Aeroacoustics, vol. 9, no. 3, pp. 273-305, May 2010.

[15] A. Afshari, M. Azarpeyvand, A. A. Dehghan, and M. Szőke, "Trailing edge noise reduction using novel surface treatments," in 22nd AIAA/CEAS Aeroacoustics Conference, 2016, 2016.

[16] G. Guidati, R. Bareiß, S. Wagner, T. Dassen, and R. Parchen, "Simulation and measurement of inflow-turbulence noise on airfoils," in 3rd AIAA/CEAS Aeroacoustics Conference, 1997, pp. 815-825. 